\title{
Factors associated with episiotomy practice in Bukavu, Democratic Republic of the Congo
}

\author{
Ntamulenga Innocent ${ }^{1,2}$, Mulongo Mbarambara Philémon ${ }^{3 *}$, Imani Prince ${ }^{1,2}$, Yatoka Justine ${ }^{3}$, \\ Mukanire Ntakwinja ${ }^{1,2}$, Nyakiyo Olivier ${ }^{1,2}$, Mukwege Denis ${ }^{1,2}$
}

\begin{abstract}
${ }^{1}$ Department of Gynecology and Obstetrics, General Referral Hospital of Panzi, Bukavu, Democratic Republic of the Congo

${ }^{2}$ Department of Medicine, Evangelic University in Africa, Bukavu, Democratic Republic of the Congo

${ }^{3}$ Department of Midwifery, Higher Institute of Medical Techniques of Bukavu, Bukavu, Democratic Republic of the Congo
\end{abstract}

Received: 19 April 2018

Accepted: 23 May 2018

\section{*Correspondence:}

Dr. Mulongo Mbarambara Philémon,

E-mail: philemon770@gmail.com

Copyright: (c) the author(s), publisher and licensee Medip Academy. This is an open-access article distributed under the terms of the Creative Commons Attribution Non-Commercial License, which permits unrestricted non-commercial use, distribution, and reproduction in any medium, provided the original work is properly cited.

\begin{abstract}
Background: The primary objective of the present study is to determine the episiotomy rate and factors associated with practice of episiotomy at the maternities in Bukavu town, South-Kivu, DRC.

Methods: A case-control study was carried out the women who underwent the episiotomy (case) and those which did not undergo episiotomy (control) over one 12 months period between January to December 2015. A total of 1878 women had a vaginal delivery at a rate of one case for one control (939 cases and 939 controls) were included. Their medical files were exploited. The factors associated with episiotomy were performed by logistic regression.

Results: The rate of episiotomy was $20.4 \%$. It was found that after the logistic regression, the Primiparity (OR $=$ $4,5 ; 95 \% \mathrm{CI}: 2,31-4,49)$, the existence of a foetal distress ( $\mathrm{OR}=4,2 ; \mathrm{IC}$ to $95 \% \mathrm{CI}: 2,36-5,29)$, the antecedent of episiotomy $(\mathrm{OR}=3,9 ; 95 \% \mathrm{CI}: 2,83-7,07)$, private character of maternity $(\mathrm{OR}=3,3 ; 95 \% \mathrm{CI}: 2,12-6,30)$ and the fact that the childbirth was directed by a doctor $(\mathrm{OR}=2,3 ; 95 \% \mathrm{CI}: 1,85-5,08)$ were strongly associated with the practice of the episiotomy in our medium of study.

Conclusions: This study showed UA-S/D ratio and UA-RI $>2$ SD are significant predictors of perinatal deaths and immediate neonatal resuscitation in preeclampsia. Acute fetal distress in labour or neonatal nursery admission could not be predicted.
\end{abstract}

Keywords: DRC, Episiotomy, Factors associated

\section{INTRODUCTION}

The episiotomy is a medial or mid-lateral surgical incision made on the perineum of a parturient to provide sufficient space to facilitate the expulsion of the child. ${ }^{1}$ Worldwide, between $9.7 \%$ and $97 \%$ of parturients undergo episiotomy. ${ }^{2}$ Reasons for episiotomy during "normal" vaginal delivery are: signs of fetal distress, poor work performance, and threat of third-degree perineal tear (including third-degree tear in previous childbirth). ${ }^{3}$ But there are huge contextual variations. Tears in the perineum are common, especially in primiparous women, but the incidence of third-degree tears justifying episiotomy is about $0.4 \%$ of deliveries. In spite of this low rate, between $63 \%$ and $100 \%$ of primiparous around the world and according to the countries, undergo an episiotomy. ${ }^{2}$ Because of the major infectious risk in developing countries, the World Health Organization (WHO) suggests reducing to less than $10 \%$ the practice in 
this context of useful episiotomies. ${ }^{4}$ This caution is confirmed by the Cochrane systematic review of episiotomy, which suggests better benefits for episiotomy "indicated" or restrictive than routine episiotomy. ${ }^{5}$

On the African continent, publications related to the practice of episiotomy have also shown enormous variations between countries but also between health facilities in the same country. In a study conducted in Morocco, the authors found an episiotomy rate of $41.3 \%$ with as explanatory variables primiparity, adolescence, vacuum extraction and the interval between birth cohorts less than 5 years. ${ }^{6}$

A retrospective review of all deliveries recorded at Jimma University Hospital in Ethiopia to determine the episiotomy rate and factors influencing this technique found a $25 \%$ episiotomy rate in 2861 vaginal deliveries. This proportion was $29 \%$ when the Forceps was used, $30 \%$ when using a suction cup. $47 \%$ of primiparous and $5 \%$ of multiparas underwent episiotomy. ${ }^{7}$

In the Democratic Republic of Congo, data on the practice of episiotomy are not available. And yet, it is one of the countries with a high birth rate and whose health system is more financed by the population.

The fact that the results of studies carried out around the world question the benefits traditionally known to episiotomy, it is important to make an overview on this practice in our city of Bukavu where no scientific evidence does not exist yet in this matter. ${ }^{8-11}$ This study is intended as an advocacy and training tool for the rationalization of the practice of episiotomies in the DRC and in low and middle-income countries. The purpose of this study was to determine the episiotomy rate and associated factors in maternity wards in Bukavu city, eastern DRC.

\section{METHODS}

\section{Study settings}

The study was conducted in the city of Bukavu which includes a provincial hospital, a university hospital, three general referral hospitals, a general hospital, five hospital health centers, twenty health centers and about ten polyclinics and medical centers.

A set of thirty-five maternities are functional in the city of Bukavu and were the subject of the present study. Depending on the technical platform, we have two strata (the hospital stratum and the health center stratum). Delivery is provided by nurses, midwives and general practitioners for the most part. Their number was 185 , including 100 nurses, 50 midwives and 35 doctors.

We conducted a case-control study using the medical records of women who gave birth vaginally in the various maternity wards in the city of Bukavu during the period from January 1 to December 31, 2015. The women who underwent episiotomy were cases and those who did not undergo episiotomy were considered to be one case for a control.

The total population of the city of Bukavu in 2015 was 876917 inhabitants of which the proportion of women of childbearing age was $21 \%(876917 \times 21) / 100: 184153$ women. The proportion of deliveries expected was $4 \%$ (4x184153) / 100: 7366 deliveries per year. The delivery rate in the Bukavu health facilities is $85 \%(7366 \times 85) /$ 100: 6261 assisted deliveries.

To account for the representativeness of the target population, we worked with a sample of $30 \%$ of assisted deliveries. And so, $(6261 \times 30) / 100: 1878$ records of women having given birth in the different maternity units of Bukavu were exploited at the rate of 939 with episiotomy and 939 deliveries without episiotomy.

\section{Inclusion Criteria}

- Delivery to take place vaginally with or without episiotomy,

- Records of the deliveries are correctly filled and available.

\section{Exclusion Criteria}

Cesarean deliveries, home deliveries and unusable records (lost or poorly completed) were the exclusion criteria.

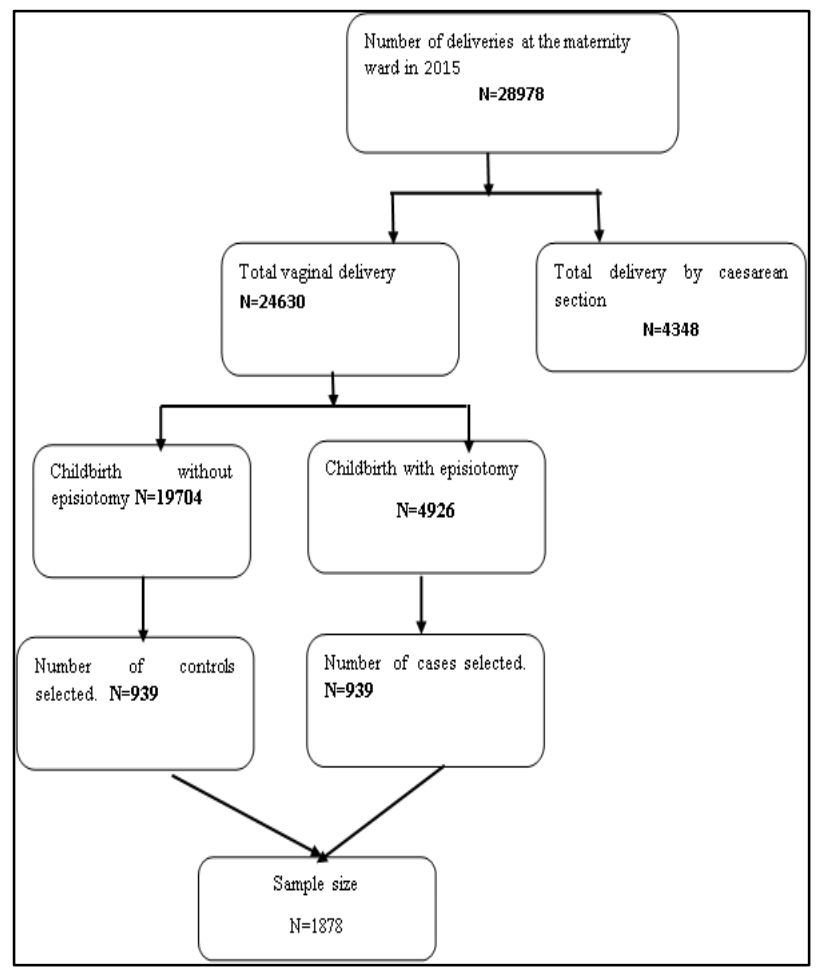

Figure 1. Processing of sample size. 


\section{Mode of collection and statistical analysis of the data}

Data collection was accomplished by using birth records routinely prepared for each delivery using a standard form for this purpose. The information on the health facility was provided by the head of the nursing service. The practice of episiotomy was the dependent variable. The other variables were the sociodemographic characteristics of the women who gave birth (age, parity, etc.), the clinical and obstetrical characteristics (history of episiotomy, hypertensive syndrome, use of oxytocin, etc.), perinatal characteristics (weight of the birth level, postpartum haemorrhage) and the characteristics of the maternities (type of maternity, technical plateau,).

Data entry and statistical analysis were performed with Excel 2013 and STATA software. SE, version 13.0. The usual descriptive statistics have been calculated.

The chi-square test and logistic regression were used for statistical analysis and comparison of factors between the two groups of women (those who underwent episiotomy and those who did not undergo episiotomy). The materiality threshold was set at 0.05 . The raw and adjusted Odds allowed to estimate the intensity of the association.

\section{Ethical considerations}

The study was approved by the Ethics Committee of the Research Center for Health Promotion of the Higher Institute of Medical Technology of Bukavu. But also, we obtained the authorization to exploit the files related to this subject from all the heads of health facilities organizing the maternity service.

\section{RESULTS}

\section{General characteristics of the study population}

In the course of 2015 , a total of 28,978 births were registered in maternity wards of health facilities in the city of Bukavu. Of these, 4926 with episiotomy is an annual rate of $20.0 \%$ overall.

The general characteristics of the women who had been found to be significantly related to the practice of episiotomy in maternity clinics in the city of Bukavu were age and parity in univariate analysis, but only parity remained significant in regression with $\mathrm{p}<0.0001$. Table 1 describes the general characteristics of the study.

The episiotomy rate was higher when the parturient had a short perineum, less than $3 \mathrm{~cm}$ with $60.9 \%$ compared to $48.0 \%$ for perineum of normal length.

This difference was found to be statistically significant between the two groups of women $(p=0.0015)$ Fetal pain objectified in a woman in childbirth was a risk factor for episiotomy compared to a woman who did not did not have fetal distress $(\mathrm{p}=0.001)$.

The history of episiotomy increased the risk of episiotomy by 3.9 compared with a woman who had never undergone an episiotomy.

Table 1: General characteristics related to the episiotomy in Bukavu, 2015.

\begin{tabular}{|c|c|c|c|c|c|c|}
\hline Associated factors & $\mathrm{n}=\mathbf{1 8 7 8}$ & \% Episiotomy & Crude OR (95\% CI) & $\mathbf{P}$ & $\begin{array}{l}\text { Adjusted OR } \\
(95 \% \mathrm{CI})\end{array}$ & $\mathbf{P}$ \\
\hline \multicolumn{7}{|l|}{ Age in years } \\
\hline$<20$ & 375 & 71.7 & $3.2(2.3-4.3)$ & 0.0001 & $2.1(0.97-2.92)$ & 0.061 \\
\hline$\geq 20$ & 1503 & 44.6 & & & & \\
\hline \multicolumn{7}{|l|}{ Education status } \\
\hline Non & 436 & 45.2 & $0.8(0.59-1.02)$ & 0.0711 & - & \\
\hline Educated & 1442 & 51.5 & & & & \\
\hline \multicolumn{7}{|l|}{ Parity } \\
\hline Primiparity & 492 & 73.3 & $4.0(3.04-5.32)$ & $<0.0001$ & $4.5(2.31-4.49)$ & $<0.0001$ \\
\hline Multiparity & 1386 & 40.5 & & & & \\
\hline \multicolumn{7}{|l|}{ Residence } \\
\hline Rural & 480 & 51.5 & $1.1(0.88-1.40)$ & 0.370 & - & \\
\hline Urban & 1398 & 48.9 & & & & \\
\hline
\end{tabular}

When the delivery was medically supervised $(66.7 \%)$, followed by $50.7 \%$ when the nurse was the head of the delivery and a low rate was observed in women whose delivery was supervised by a midwife (35.8) and therefore, women who are followed by a doctor were at high risk of episiotomy compared to women who were followed by a midwife $(p=0.004)$. According to the private and public nature of the health facility, the episiotomy rates recorded in a private maternity hospital were higher than in public maternity hospitals $(68.0 \%$ 
versus $46.8 \%$ ) with a statistically significant difference ( $\mathrm{p}$ $=0.001)$. According to the level of the health facility, women delivered more episiotomy in health centers (1st level with $59.4 \%$ ) than women who gave birth in 2nd level hospitals with 49.3\%). The difference between episiotomy rates by level of structure was significant with $\mathrm{p}=0.024$. There was no statistically significant difference in episiotomy rates between oxytocin $(\mathrm{p}=$ 0.122 ) and vasculoneural syndrome $(p=0.277)$. The factors favoring the practice of episiotomy in Bukavu health facilities are presented in Table 2.

Table 2: Factors associated with episiotomy in Bukavu, 2015.

\begin{tabular}{|c|c|c|c|c|c|c|}
\hline Associated factors & $\mathrm{n}=\mathbf{1 8 7 8}$ & \% Episiotomy & $\begin{array}{l}\text { Crude OR } \\
(95 \% \mathrm{CI})\end{array}$ & $\mathbf{P}$ & $\begin{array}{l}\text { Adjusted OR } \\
(95 \% \mathrm{CI})\end{array}$ & p \\
\hline \multicolumn{7}{|l|}{ State of perinea } \\
\hline Short (abnormal) & 343 & 60.9 & $1.7(1.21-2.33)$ & 0.0015 & $1.2(0.65-2.22)$ & 0.535 \\
\hline Normal (long) & 1535 & 48.0 & 1.0 & & & \\
\hline \multicolumn{7}{|c|}{ Vasculo-renal syndrome } \\
\hline Yes & 250 & 43.5 & $1.3(0.78-2.29)$ & 0.277 & & \\
\hline No & 1528 & 50.9 & 1.0 & & & \\
\hline \multicolumn{7}{|l|}{ Oxytocin use } \\
\hline Yes & 242 & 50.2 & $1.5(0.98-3.58)$ & 0.122 & & \\
\hline No & 1636 & 45.8 & 1.0 & & & \\
\hline \multicolumn{7}{|l|}{ Childbirth attendant } \\
\hline A physician (doctor) & 124 & 66.7 & $2.1(1.21-3.55)$ & 0.006 & $2.3(1.85-5.08)$ & 0.004 \\
\hline A Nurse & 1250 & 50.7 & $1.2(0.45-1.57)$ & 0.084 & - & \\
\hline A Midwife & 504 & 35.8 & $0.7(0.36-0.92)$ & 0.027 & $0.6(0.32-0.85)$ & 0.022 \\
\hline \multicolumn{7}{|l|}{ Fetal distress } \\
\hline Yes & 332 & 79.1 & $4.3(1.97-4.55)$ & 0.001 & $4.2(2.36-5.99)$ & 0,001 \\
\hline No & 1546 & 35.2 & 1.0 & & & \\
\hline \multicolumn{7}{|l|}{ Previous episiotomy } \\
\hline Yes & 476 & 78.1 & $3.9(1.56-9.85)$ & 0.001 & $3.9(2.83-7.07)$ & 0.001 \\
\hline No & 1402 & 38.2 & 1.0 & & & \\
\hline \multicolumn{7}{|l|}{ State of the structure } \\
\hline Private & 651 & 68.0 & $3.4(1.43-4.06)$ & 0.001 & $3.3(2.12-6.30)$ & 0.001 \\
\hline Public & 1227 & 46.8 & 1.0 & & & \\
\hline \multicolumn{7}{|l|}{ Level of the structure } \\
\hline $1^{\text {st }}$ level & 1113 & 59.4 & $2.2(1.64-3.09)$ & 0.035 & $2.0(1.89-4.99)$ & 0.014 \\
\hline 2nd level & 765 & 49.3 & 1.0 & & & \\
\hline
\end{tabular}

\section{DISCUSSION}

This study attempted to retrospectively document the proportion of episiotomy and its associated factors in the city of Bukavu. In present study, we found an episiotomy rate of $20 \%$ for all vaginal deliveries in health facilities in the city of Bukavu during 2015.

Although there is no ideal rate for the practice of episiotomy around the world, let us admit however that the overall rate found in this study is far superior to the rate of less than $10 \%$ recommended by the WHO. ${ }^{4}$ Our rate remains higher than the rate found $(41.28 \%$ ) by a study conducted in Morocco, and that of $25 \%$ of another study conducted in southwestern Ethiopia, at a rate of $41.4 \% . \%$ in the northern region of Ethiopia and at $46.6 \%$ in Nigeria. ${ }^{6,7,12,13}$ The rate found in this study could be explained by more than one reason including the fact that women who give birth for the first time were almost systematically treated with an episiotomy, on the other hand, in our environment of Bukavu, the episiotomy is considered a usual practice (routine). Finally, the selffinancing context in which most of the health structures in the community operate would justify the use of episiotomy.

The differences in the rates observed between studies could be justified by more than one reason, in particular the methodology used, the health system of each country, the basic training of each practitioner who led the delivery, and the time effect that supposes that with the quality care approach currently in vogue, the trainings reduce interventions around the delivery, especially the episiotomy. It is these multiple variations of episiotomy rates that are observed at the international, regional and even national levels, which, moreover, were highly controversial, WHO has once again recommended that only so-called necessary episiotomies be performed. ${ }^{14}$ 
The other important piece of information in this study was the identification of factors favoring the use of episiotomy in present study setting. The factors associated with the Bukavu episiotomy practice were primiparity, fetal distress, episiotomy history, the fact that the delivery was supervised by a physician, the private nature of the facility, and the fact that the delivery was directed to the health centers ( $1^{\text {st }}$ step). Our surveys corroborate most studies in both developing and developed countries. ${ }^{15-17}$

With respect to parity, it was noted that primiparous women were at greater risk of episiotomy compared to multiparas with an OR of 4.5 (95\% CI: 2.31-4.49 and $\mathrm{p}=$ 0.001). This has been widely documented by other studies on this subject including Raisanen, De Alavande and Mitiku. ${ }^{17,18,19}$

The only explanation for this result is only the traditional indication of episiotomy in women who come to give birth for the first time and this denotes the weight of routine in care practices in Bukavu. The integration of the quality of care approach is essential for professionals to provide only care based on scientific evidence.

The occurrence of fetal distress during child labor multiplied by 4.2 the risk of having an episiotomy compared to a woman whose fetus did not develop any pain ever undergone episiotomy. Riesco et al and AlGhammari were able to find similar results. ${ }^{20}$ The desire to hasten delivery in order to save to improve the neonatal prognosis would justify this indication until today. ${ }^{21}$ The history of episiotomy multiplied the risk of episiotomy by 3.9 compared to a woman who had never had an episiotomy. This is related to the repair that has been done and the complications that arise from episiotomy for future deliveries. ${ }^{22}$

The episiotomy rate was as high when the delivery was supervised by a doctor as when the delivery was managed by a midwife $(66.7 \%$ versus 35.8 with $\mathrm{p}=0.004)$ as was also mentioned in the study by Eason et al following the desire to want to quickly finish the delivery. ${ }^{23}$

According to the private and public nature of the health facility, the episiotomy rates recorded in a private maternity hospital were higher than in public maternity hospitals $(68.0 \%$ versus $46.8 \%)$ with a statistically significant difference $(p=0.001)$. Nancy would have noticed that the private trainings practiced more episiotomy than the public formations. ${ }^{24} \mathrm{~A}$ financial reason underlies this practice especially when the providers prioritize the acts that bring a little more money into the health facility. According to the level of the health facility, women delivered more episiotomy in health centers ( $1^{\text {st }}$ level with $\left.59.4 \%\right)$ than women who gave birth in 2 nd level hospitals with $49.3 \%){ }^{25}$ Our results are contrary to those who found that the secondary and tertiary level practiced more episiotomy than the primary level. We believe that the fact that no subsidy is received from the government for the operation of health facilities, the use of episiotomy is a source of selffinancing.

\section{CONCLUSION}

The practice of episiotomy is common in maternity hospitals in the city of Bukavu. The predictive model of the practice of episiotomy retained primiparity, the existence of fetal distress, the antecedent of episiotomy, the private nature of motherhood, and the fact that delivery was supervised by a physician. Other gentle obstetric maneuvers are to be explored. The use of episiotomy should be an exception, especially in the context of women with unknown serology of HIV. Continuing education in emergency obstetric and neonatal care would be important for improving the quality of care in maternity wards in the city of Bukavu.

\section{ACKNOWLEDGMENTS}

Our feelings of gratitude are addressed to all authorities of different structures that have been the subject of this study. We also think of the team spirit that characterized the investigators when collecting the data.

\section{Funding: No funding sources \\ Conflict of interest: None declared}

Ethical approval: The study was approved by the Institutional Ethics Committee

\section{REFERENCES}

1. Jovanovic N, Kocijancic D, Terzic M. Current approach to episiotomy: Inevitable or unnecessary? Open Medicine. 2011;6(6):685-90.

2. Graham ID, Carroli G, Davies C, Medves JM. Episiotomy rates around the world: an update. Birth. 2015;32(3):219-23.

3. Bansal RK, Tan WM, Ecker JL, Bishop JT, Kilpatrick SJ. Is there a benefit to episiotomy at spontaneous vaginal delivery? A natural experiment. Am J Obstet Gynecol. 1996;175(4),897-901.

4. World Health Organization. Care in normal birth: a practical guide. Geneve: WHO; 1996.

5. Carroli G, Mignini L. Episiotomía para el parto vaginal (Revisión Cochrane traducida). Cochrane Database of Systematic Reviews. 2012;11: CD000081.

6. Bakkali MEL, Azzouzi Y, Khadmaoui A, Ouaaziz NA, Arfaoui A. Risk factors associated with the practice of episiotomy and the occurrence of perineal tears in mothers at the maternity hospital of Chérif Idrissi hospital in the region of Gharb Chrarda Bni Hssen (Morocco). Int J Inno App Stu. 2014;7(3):911-9.

7. Marai W. A two years retrospective review of episiotomy at Jimma Teaching Hospital, southwestern Ethiopia. Ethiop Med J. 2002;40 (2):141-8. 
8. Diniz SG, Chacham AS. "The cut above" and "the cut below": the abuse of caesareans and episiotomy in Sao Paulo, Brazil. Reprod Health Matters. 2004;12:100-10.

9. Argentine Episiotomy Trial Collaborative Group. Routine versus selective episiotomy: a randomised controlled trial. Lancet. 1993;342:1517-8.

10. Jander C, Lyrenas S. Third and fourth degree perineal tears. Acta Obstet Gynecol Scand. 2001;80 (3):229-34.

11. Clesse C, Lighezzolo-Alnot J, Hamlin S, De Lavergne S, Scheffler M. The practice of episiotomy in France 10 years after the CNGOF recommendations: what state of the art? Gynecol Obstet Fertil. 2016;44(4):232-8.

12. Yemane Y, Sahile E, Alehegn A, Girma A, Robles $\mathrm{C}$, Kebedde $\mathrm{S}$ et al. Assessment of the proportion and associated factors of episiotomy at public health institutions of Axum Town, Tigray Region, North Ethiopia, 2015. Crit Care Obstet Gynecol. 2017;3:11.

13. Belloo O, Anorlu AI. Episiotomies in Nigeria: should their use be restricted? Niger Postgrad Med J. 2002;99:13-6.

14. Liljestrand J. Episiotomy for vaginal birth: RHL commentary (last revised: 20 October 2003). The WHO Reproductive Health Library; Geneva: World Health Organization.

15. Izuka E, Prevalence and predictors of episiotomy among women at first birth in enugu South East Nigeria. Ann Med Health Sci Res. 2014;4:928.

16. Hueston WJ. Applegate JA, Mansfield CJ, King DE, McClaffin RR. Practice variations between family physicians and obstetricians in the management of low risk pregnancies. J Fam Pract. 1995;40(4):34551.

17. Raisanen S, Vehvila“inen-Julkunen K, Heinonen S. Need for and consequences of episiotomy in vaginal birth: a critical approach. Midwifery. 2010;26:34856 .
18. Alayande BT, Amole IO, Akin D. Relative frequency and predictors of episiotomy in Ogbomoso, Nigeria. Int J Med. 2012;7:2.

19. Mitiku G, Beyene W, Geremew M. Assessment of Episiotomy Practice in Mizan-Aman General Hospital, Ethiopia. J Health Med Nursing. 2015;20:12-20.

20. Riesco LG, Costa ASC, Almeida SFS, Basile AL de O, Oliveira SMJV. Episiotomy, laceration and perineal integrity in normal births: analysis of associated factors. Rev enferm UERJ [Internet]. 2011;19(1):77-83.

21. Al-Ghammari K. Predictors of routine episiotomy in primigravida. Applied Nursing Res. 2016;29:131-5.

22. Leeman L, Fullilove AM, Borders N, Manocchio R, Albers LL, Rogers RG. Postpartum perineal pain in a low episiotomy setting: association with severity of genital trauma, labor care, and birth variables. Birth. 2009;36:283-8.

23. Eason E, Feldman P. Much ado about a little cut: is episiotomy worthwhile? Obstet Gynecol 2000; 95:616-8.

24. Nancy L.S. Howden, Anne M. Weber, Leslie A Meyn. Episiotomy use among residents and faculty compared with private practitioners. Obstetrics and Gynecol. 2004; 103:114-8.

25. Faruel-Fosse H, Vendittelli F. Can we reduce the episiotomy rate? J Gynecol Obstet Biol Reprod (Paris). 2006;35(1):1S68-76.

Cite this article as: Innocent N, Philémon MM, Prince I, Justine Y, Ntakwinja M, Olivier N et al, Factors associated with episiotomy practice in Bukavu, Democratic Republic of the Congo. Int J Reprod Contracept Obstet Gynecol 2018;7:2553-8. 